\title{
Application of the Dempster-Shafer Theory to the Classification of Pixels from Aster Satellite Images and Spectral Indices
}

\author{
Jean-Claude Okaingni1,2, Sié Ouattara1,2, Adles Francis Kouassi1,2,3, Adama Koné1,2, \\ Wognin Joseph Vangah ${ }^{1,2}$, Alain Clement ${ }^{4}$ \\ ${ }^{1}$ Laboratory of Signals and Electrical Systems (L2SE)), Institut National Polytechnique Houphouët Boigny, Yamoussoukro, \\ Cote D'Ivoire \\ ${ }^{2}$ Institut National Polytechnique Houphouët Boigny (INPHB), Yamoussoukro, Cote D’Ivoire \\ ${ }^{3}$ Ecole Supérieure des Technologies de l'Information et de la Communication (ESATIC), Abidjan, Cote D’Ivoire \\ ${ }^{4}$ Institut Universitaire de Technologie d'Angers (IUT), Angers, France \\ Email: sie_ouat@yahoo.fr
}

How to cite this paper: Okaingni, J.-C., Ouattara, S., Kouassi, A.F., Koné, A., Vangah, W.J., Clement, A. (2017) Application of the Dempster-Shafer Theory to the Classification of Pixels from Aster Satellite Images and Spectral Indices. Journal of Applied Mathematics and Physics, 5, 1462-1477. https://doi.org/10.4236/jamp.2017.57120

Received: June 20, 2017

Accepted: July 21, 2017

Published: July 24, 2017

Copyright (C) 2017 by authors and Scientific Research Publishing Inc. This work is licensed under the Creative Commons Attribution International License (CC BY 4.0).

http://creativecommons.org/licenses/by/4.0/

\section{(c) (i) Open Access}

\begin{abstract}
In this paper, it is proposed to apply the Dempster-Shafer Theory (DST) or the theory of evidence to map vegetation, aquatic and mineral surfaces with a view to detecting potential areas of observation of outcrops of geological formations (rocks, breastplates, regolith, etc.). The proposed approach consists in aggregating information by using the DST. From pretreated Aster satellite images (geo-referencing, geometric correction and resampling at $15 \mathrm{~m}$ ), newchannels were produced by determining the spectral indices NDVI, MNDWI and NDBaI. Then, the DST formalism was modeled and generated under the MATLAB software, an image segmented into six classes including three absolute classes $(E, V, M)$ and three classes of confusion $(\{E, V\},\{M, V\},\{E, M\})$. The control on the land, based on geographic coordinates of pixels of different classes on said image, has made it possible to make a concordant interpretation thereof. Our contribution lies in taking into account imperfections (inaccuracies and uncertainties) related to source information by using mass functions based on a simple support model (two focal elements: the discernment framework and the potential set of belonging of the pixel to be classified) with a normal law for the good management of these.
\end{abstract}

\section{Keywords}

Dempster-Shafer Theory, Belief Functions, Source Modeling, Aster Satellite Images, Spectral Indices, Classification 


\section{Introduction}

The mapping of the state of the surfaces of the Earth has been the subject of several works. Researchers have used the use of spectral indices to classify satellite images. These indices have been used for the mapping of vegetated surfaces, water surfaces and surfaces of bare soil and built-up. However, it is difficult to determine the appropriate threshold values for ideal results ([1] [2]). This gives rise to uncertainties and inaccuracies in the information produced by the images associated with said indices. So, we propose to introduce the belief functions through the Dempster-Shafer theory to take into account and manage the possible imperfections related to the images associated with the indices in order to improve the decision-making in the assignment of a class to each pixel of the image.

The general objective of the study is to develop a pixel classification model using the Dempster-Shafer theory, spectral indices NDVI (Normalized Difference Vegetation Index), MNDWI (Modification of Normalized Difference Water Index) and $\mathrm{NDBaI}$ (Normalized Difference Bare Index), and ASTER satellite images. It acts specifically first, to model the framework of discernment and belief functions, then define the decision criteria and write algorithms and programming codes under the MATLAB software; finally realize and evaluate classified image.

This paper, which proposes to report on the work carried out, presents successively the belief functions, the material used, the methodological approach that guided the work and the results obtained.

\section{Belief Functions}

Exclusive use of belief functions and remote sensing images with data from different sensors, aims to improve classifications ([3] [4] [5]) to detect change or changing scales and/or mapping objects, parameters or phenomena ([6] [7]).

\subsection{Basic Principle}

The basic principle is taken from the work of [7].

Let $\Omega=\left\{C_{1}, \cdots, C_{N}\right\}$, the set of possible $N$ classes for $x$, called discernment framework. The theory of belief functions is based on the manipulation of mass functions defined on the power set of $\Omega$, denoted by $2^{\Omega}$, the set of the $2^{N}$ disjunctions of $\Omega$, instead of being restricted to $\Omega$ as would the theory of probabilities.

We then define an initial mass function $m$ of $2^{\Omega}$ with values in $[0,1]$ satisfying the following conditions of Equation (1):

$$
\left\{\begin{array}{l}
\sum_{A \in 2^{\Omega}} m(A)=1 \\
m(\varnothing)=0
\end{array}\right.
$$

where $\varnothing$ is the empty set.

The value $m(A)$ quantifies the belief that the class sought belongs to the subset $A$ of $\Omega$ (and not to any other subset of $A$ ).

The subsets $A$ such that $m(A)>0$ are called focal elements.

Two functions of initial mass $m_{1}$ and $m_{2}$ representing the respective informa- 
tion of two different sources can be combined according to the Dempster rule [7] in Equation (2):

$$
m(A)=\frac{\sum_{B \cap C=A} m_{1}(B)^{*} m_{2}(C)}{1-K}, \forall A \in 2^{\Omega} \backslash\{\varnothing\} ; \forall B, C \in 2^{\Omega}
$$

The term $K$ is called the inconsistency of the fusion and can be interpreted as a measure of conflict. It corresponds to the mass of the empty set. Equation (3) gives its expression:

$$
K=\sum_{B \cap C=\varnothing} m_{1}(B) * m_{2}(C), \quad \forall B, C \in 2^{\Omega}
$$

If $K=1$, the combination of information sources is impossible. This means that the sources are totally in conflict. They give contradictory information of the object of interest.

\subsection{Measuring Evidence}

The measurement of evidence is carried out through decision rules. We denote several decision rules ([8] [9] [10]). The most used decision rules are based on credibility functions and plausibility functions.

The credibility Bel and plausibility PIs functions are defined from $2^{\Omega}$ in $[0,1]$ and are given respectively by Equations ((4) and (5)):

$$
\begin{gathered}
\operatorname{Bel}(A)=\sum_{B \in 2^{\Omega}, B \subseteq A} m(B), \quad \forall A \in 2^{\Omega} \\
\operatorname{Pls}(A)=\sum_{B \in 2^{\Omega}, B \cap A \neq \varnothing} m(B), \quad \forall A \in 2^{\Omega}
\end{gathered}
$$

Credibility functions measure to what extent information given by a source supports hypothesis $A$, while plausibility functions measure how well information from a source does not contradict hypothesis $A$.

The values of the credibility $\operatorname{Bel}(A)$ and plausibility $\operatorname{Pls}(A)$ functions of hypothesis $A$ can be respectively interpreted as the minimum and maximum uncertainty values around $A$. So, the interval $[\operatorname{Bel}(A), \operatorname{Pls}(A)]$, called confidence interval, quantifies ignorance of source on hypothesis $A$.

Thus, the class $C$ retained for $x$ is the element of $\Omega$ whose value is the greatest with respect to the criterion of decision chosen either the maximum of credibility or the maximum of plausibility. These criteria are given by Equations ((6) and (7)) respectively:

$$
\begin{aligned}
& C^{*}=\operatorname{Arg}\left\{\max _{C_{i} \in \Omega}\left[\operatorname{Bel}\left(C_{i}\right)\right]\right\} \\
& C^{*}=\operatorname{Arg}\left\{\max _{C_{i} \in \Omega}\left[\operatorname{Pls}\left(C_{i}\right)\right]\right\}
\end{aligned}
$$

\section{Materials and Methods}

\subsection{Materials}

The tools used are software and data.

With regard to the software, it was first used ENVI 4.7 to preprocessing 
ASTER images, then MATLAB to develop a model based on the use of the spectral indices $N D V I, M N D W I$ and $N D B a I$, and the theory of the belief functions for the classification of aquatic, mineral and vegetated surfaces.

The data for this study are of two types: field data and remote sensing data.

Field data consists of geographical coordinates of fixed points and outcrops. The geometrical and geological characteristics of these outcrops were also recorded.

The remote sensing data used are derived from the ASTER sensor and are rectified satellite images of the scene AST_L1A_00301102004105832. This sensor has 14 bands with a broad spectral region covering the visible and near infrared (VNIR-Visible and Near Infrared), the medium infrared (SWIR-Short-Wave Infrared: Tape 4, Band 5, Band 6, Band 7, Band 8 and Band 9) and Thermal Infrared (TIR-Thermal Infrared: Band 10, Band 11, Band 12, Band 13 and Band $14)$.

The spatial resolution associated with the said images is $15 \mathrm{~m}$ in the visible and the near infrared, $30 \mathrm{~m}$ in the medium infrared and $90 \mathrm{~m}$ in the thermal infrared.

\subsection{Methods}

The approach used consisted first of a preprocessing on the ASTER satellite images under ENVI, and then it was developed a classification model based on the calculation of spectral indices ( $N D V I, M N D W I$ and $N D B a I$ ) and the use of the theory of belief functions. Concretely, it was a question of modeling the discernment framework, the mass functions as well as the functions of measuring the evidence, and defining the decision criteria. In addition, algorithms and programming codes in language were realized under Matlab software and the classified image was generated and evaluated.

\subsubsection{Preprocessing}

In order to benefit from the totality and the quality of the spatial resolutions and the spectral resolutions, the said ASTER satellite images have been subject to georeferencing, geometric correction and resampling to create a compatible database, from the 14 bands.

First, georeferencing was performed for each band using the k-nearest neighbors method; then the geometric correction was made from 100 bitter points, chosen covering uniformly the ASTER scene of interest, with the bilinear method; finally, the sampling, at a step of $15 \mathrm{~m}$ with the bilinear method, is carried out for the SWIR (bands 4, 5, 6, 7, 8 and 9) and TIR (bands 10, 11, 12, 13 and 14) bands.

Georeferencing and geometric correction make it possible to make these satellite images superimposable on others georeferenced supports in the same coordinate system.

\subsubsection{Development of the Model}

1) Modeling of the framework of discernment

Any portion of the Earth's surface can be a combination of three main entities: 
a vegetated surface, an aquatic surface and a mineral surface.

In this study, a vegetated area is an area of natural and/or cultural plants; an aquatic surface is a zone of natural and/or artificial watercourses and/or water bodies; a mineral surface is an area covered by soil, rock outcrops and/or built-up.

The smaller the surface portion, the less it will contain different entities. So, an area of $15 \mathrm{~m} \times 15 \mathrm{~m}$ could discriminate as much as possible vegetal surfaces, aquatic surfaces and mineral surfaces.

Therefore, the adopted discernment framework in Equation (8):

$$
\Omega=\{V, E, M\}
$$

$V$ : vegetated surface

$E$ : aquatic surface

M: mineral surface

\section{2) Modeling of information sources}

The sources of information considered in this study are the images produced by the new channels obtained from the calculation of the spectral indices NDVI, $M N D W I$ and $N D B a I$.

$N D V I$ is a normalized vegetation index [11]. It is used by several authors to discriminate the vegetation of bare soils because of its simplicity of calculation, its normalized character and its reputation for less sensitivity (compared to reflectance) with external factors such as Optical properties of the soil, geometry of illumination or atmospheric effects. It is given by Equation (9):

$$
N D V I=\frac{\rho(\text { band } 3)-\rho(\text { band } 2)}{\rho(\text { band } 3)+\rho(\text { band } 2)}
$$

$\rho$ (band 3): Reflectance in the near infrared

$\rho$ (band 2): Reflectance in the red (visible)

The $M N D W I$ is a normalized water index that highlights water surfaces and not moisture in plants [12]. It is given by Equation (10):

$$
M N D W I=\frac{\rho(\text { band } 2)-\rho(\text { band } 7)}{\rho(\text { band } 2)+\rho(\text { band } 7)}
$$

$\rho($ band 7) : Reflectance in the medium infrared

$\rho$ (band 2): Reflectance in the green (visible)

$\mathrm{NDBaI}$ is a normalized bareness index to discriminate the mineral surfaces of bare soils [13]. Its expression is given by Equation (11):

$$
N D B a I=\frac{\rho(\text { band } 14)-\rho(\text { band } 7)}{\rho(\text { band } 14)+\rho(\text { band } 7)}
$$

$\rho($ band 14) : Reflectance in thermal infrared

$\rho($ band 7$)$ : Reflectance in mean-infrared

On the basis of the aforementioned spectral indices, the detection of segmentation thresholds was performed by learning for each source taking into account those proposed by said authors. Thus, the thresholds used are shown in Table 1. 
Table 1. Segmentation thresholds of NDVI, MNDWI and NDBaI.

\begin{tabular}{cccccccc}
\hline & & $N D V I=X$ & \multicolumn{2}{c}{$M N D W I=Y$} & \multicolumn{2}{c}{$N D B a I=Z$} \\
\hline Thresholds & $X \leq-0.9$ & $-0.9<X \leq 0.1$ & $0.1<X$ & $Y \leq 0.9$ & $0.9<Y$ & $Z<-0.1$ & $-0.1 \leq Z$ \\
Entity & $E$ & $M$ & $V$ & $\{M, V\}$ & $E$ & $\{E, V\}$ & $M$ \\
\hline
\end{tabular}

\section{3) Modeling mass functions}

The sources mass functions are set to:

$$
2^{\Omega}=\{\phi, V, E, M,\{V, E\},\{V, M\},\{E, M\}, \Omega\}
$$

Considering the normal distribution of variable $x$ and parameters $\mu_{A}$ et $\sigma_{A}$, in Equation (12):

$$
N\left(x, \mu_{A}, \sigma_{A}\right)=\frac{1}{\sigma_{A} \sqrt{2 \pi}} \exp \left(-\frac{\left(x-\mu_{A}\right)^{2}}{2 \sigma_{A}^{2}}\right)
$$

with $\mu_{A}$ et $\sigma_{A}$ respectively the mean and the standard deviation of the data $x$ belonging to $A$, the mass functions of the sources are then defined by (13)-(19).

\section{- NDVI function mass}

With $N D V I(x)$ : value of the pixel $x$ of the $N D V I$ image, we have: if $\operatorname{NDVI}(x) \leq-0.9$ then:

$$
\left\{\begin{array}{l}
N D V I_{x}(E)=\sigma_{E} \sqrt{2 \pi} N\left(N D V I(x), \mu_{E}, \sigma_{E}\right) \\
N D V I_{x}(\Omega)=1-N D V I_{x}(E) \\
N D V I_{x}(A)=0 \quad \forall A \in 2^{\Omega}-\{E, \Omega\}
\end{array}\right.
$$

if $-0.9 \prec N D V I(x) \leq 0.1$ then:

$$
\left\{\begin{array}{l}
\operatorname{NDVI}_{x}(M)=\sigma_{M} \sqrt{2 \pi} N\left(N D V I(x), \mu_{M}, \sigma_{M}\right) \\
\operatorname{NDVI}_{x}(\Omega)=1-N D V I_{x}(M) \\
\operatorname{NDVI}_{x}(A)=0 \quad \forall A \in 2^{\Omega}-\{M, \Omega\}
\end{array}\right.
$$

if $\operatorname{NDVI}(x) \succ 0.1$ then:

$$
\left\{\begin{array}{l}
N D V I_{x}(V)=\sigma_{V} \sqrt{2 \pi} N\left(N D V I(x), \mu_{V}, \sigma_{V}\right) \\
N D V I_{x}(\Omega)=1-N D V I_{x}(V) \\
N D V I_{x}(A)=0 \quad \forall A \in 2^{\Omega}-\{V, \Omega\}
\end{array}\right.
$$

- MNDWI mass function

With $M N D W I(x)$ : value of the pixel $x$ of the $M N D W I$ image, we have: if $\operatorname{MNDWI}(x) \leq 0.9$ then:

$$
\left\{\begin{array}{l}
\operatorname{MNDWI}_{x}(\{M, V\})=\sigma_{\{M, V\}} \sqrt{2 \pi} N\left(\operatorname{MNDWI}(x), \mu_{\{M, V\}}, \sigma_{\{M, V\}}\right) \\
\operatorname{MNDWI}_{x}(\Omega)=1-\operatorname{MNDWI}_{x}(\{M, V\}) \\
\operatorname{MNDWI}_{x}(A)=0 \quad \forall A \in 2^{\Omega}-\{\{M, V\}, \Omega\}
\end{array}\right.
$$

if $\operatorname{MNDWI}(x) \succ 0.9$ then: 


$$
\left\{\begin{array}{l}
\operatorname{MNDWI}_{x}(E)=\sigma_{E} \sqrt{2 \pi} N\left(\operatorname{MNDWI}(x), \mu_{E}, \sigma_{E}\right) \\
\operatorname{MNDWI}_{x}(\Omega)=1-\operatorname{MNDWI}_{x}(E) \\
\operatorname{MNDWI}_{x}(A)=0 \quad \forall A \in 2^{\Omega}-\{\Omega, E\}
\end{array}\right.
$$

\section{- NDBaI mass function}

With $N D B a I(x)$ : value of the pixel $x$ of the NDBaI image, we have: if $\operatorname{NDBaI}(x) \prec-0.1$ then:

$$
\left\{\begin{array}{l}
\operatorname{NDBaI}_{x}(\{E, V\})=\sigma_{\{E, V\}} \sqrt{2 \pi} N\left(\operatorname{NDBaI}(x), \mu_{\{E, V\}}, \sigma_{\{E, V\}}\right) \\
\operatorname{NDBaI}_{x}(\Omega)=1-\operatorname{NDBaI}_{x}(\{E, V\}) \\
\operatorname{NDBaI}_{x}(A)=0 \quad \forall A \in 2^{\Omega}-\{\Omega,\{E, V\}\}
\end{array}\right.
$$

if $\operatorname{NDBaI}(x) \geq-0.1$ then:

$$
\left\{\begin{array}{l}
\operatorname{NDBaI}_{x}(M)=\sigma_{M} \sqrt{2 \pi} N\left(\operatorname{NDBaI}(x), \mu_{M}, \sigma_{M}\right) \\
\operatorname{NDBaI}_{x}(\Omega)=1-\operatorname{NDBaI}_{x}(M) \\
\operatorname{NDBaI}_{x}(A)=0 \quad \forall A \in 2^{\Omega}-\{\Omega, M\}
\end{array}\right.
$$

Source focal elements $\mathrm{S}_{1}=N D V I, \mathrm{~S}_{2}=M N D W I$ et $\mathrm{S}_{3}=N D B a I$ are reported in Table 2.

\section{- Combined mass function}

The combined mass function is realized in codes according to the twelve situations generated by the thresholding conditions of $S_{1}(x), S_{2}(x)$ and $S_{3}(x)$, using the Dempster combination rule. Thus, for each situation, the combined mass function of the Equation (20) is generated in the planes $\mathrm{P}_{1}, \mathrm{P}_{2}$ and $\mathrm{P}_{3}$ $\left(\mathrm{P}_{1} \mathrm{P}_{2} \mathrm{P}_{3}\right)$, from the intersection triplet formed by the focal elements of the

Table 2. Focal elements of the sources $S_{1}, S_{2}$ and $S_{3}$ according to the thresholding conditions on $\mathrm{S}_{1}(x), \mathrm{S}_{2}(x)$ and $\mathrm{S}_{3}(x)$.

\begin{tabular}{ccccccc}
\hline & \multicolumn{3}{c}{ Conditions } & \multicolumn{3}{c}{ Focal elements } \\
\cline { 2 - 6 } Situation N & $\mathrm{S}_{1}(\boldsymbol{x})=X_{1}$ & $\mathrm{~S}_{2}(\boldsymbol{x})=X_{2}$ & $\mathrm{~S}_{3}(\boldsymbol{x})=X_{3}$ & $\mathrm{~S}_{1}$ & $\mathrm{~S}_{2}$ & $\mathrm{~S}_{3}$ \\
\hline 1 & $X_{1} \leq-0.9$ & $X_{2}>0.9$ & $X_{3} \geq-0.1$ & $\{E, \Omega\}$ & $\{E, \Omega\}$ & $\{M, \Omega\}$ \\
2 & $X_{1} \leq-0.9$ & $X_{2}>0.9$ & $X_{3}<-0.1$ & $\{E, \Omega\}$ & $\{E, \Omega\}$ & $\{\{E, V\}, \Omega\}$ \\
3 & $X_{1} \leq-0.9$ & $X_{2} \leq 0.9$ & $X_{3} \geq-0.1$ & $\{E, \Omega\}$ & $\{\{M, V\}, \Omega\}$ & $\{M, \Omega\}$ \\
4 & $X_{1} \leq-0.9$ & $X_{2} \leq 0.9$ & $X_{3}<-0.1$ & $\{E, \Omega\}$ & $\{\{M, V\}, \Omega\}$ & $\{\{E, V\}, \Omega\}$ \\
5 & $X_{1}>0.1$ & $X_{2}>0.9$ & $X_{3} \geq-0.1$ & $\{V, \Omega\}$ & $\{E, \Omega\}$ & $\{M, \Omega\}$ \\
6 & $X_{1}>0.1$ & $X_{2}>0.9$ & $X_{3}<-0.1$ & $\{V, \Omega\}$ & $\{E, \Omega\}$ & $\{\{E, V\}, \Omega\}$ \\
7 & $X_{1}>0.1$ & $X_{2} \leq 0.9$ & $X_{3} \geq-0.1$ & $\{V, \Omega\}$ & $\{\{M, V\}, \Omega\}$ & $\{M, \Omega\}$ \\
8 & $X_{1}>0.1$ & $X_{2} \leq 0.9$ & $X_{3}<-0.1$ & $\{V, \Omega\}$ & $\{\{M, V\}, \Omega\}$ & $\{\{E, V\}, \Omega\}$ \\
9 & $-0.9<X_{1} \leq 0.1$ & $X_{2}>0.9$ & $X_{3} \geq-0.1$ & $\{M, \Omega\}$ & $\{E, \Omega\}$ & $\{M, \Omega\}$ \\
10 & $-0.9<X_{1} \leq 0.1$ & $X_{2}>0.9$ & $X_{3}<-0.1$ & $\{M, \Omega\}$ & $\{E, \Omega\}$ & $\{\{E, V\}, \Omega\}$ \\
11 & $-0.9<X_{1} \leq 0.1$ & $X_{2} \leq 0.9$ & $X_{3} \geq-0.1$ & $\{M, \Omega\}$ & $\{\{M, V\}, \Omega\}$ & $\{M, \Omega\}$ \\
12 & $-0.9<X_{1} \leq 0.1$ & $X_{2} \leq 0.9$ & $X_{3}<-0.1$ & $\{M, \Omega\}$ & $\{\{M, V\}, \Omega\}$ & $\{\{E, V\}, \Omega\}$ \\
\hline
\end{tabular}


Table 3. Coding in the planes $\mathrm{P}_{1} \mathrm{P}_{2} \mathrm{P}_{3}$ of the different intersections giving each focal element of $2^{\Omega}$.

\begin{tabular}{|c|c|c|c|c|c|c|c|}
\hline & $\phi$ & $E$ & $V$ & $M$ & $\{E, V\}$ & $\{M, V\}$ & $\Omega$ \\
\hline Code (1) & $111 ; 131 ; 411$ & $113 ; 133 ; 413$ & & 431 & & & 433 \\
\hline Code (2) & & $112 ; 113 ; 132 ; 133 ; 412 ; 413$ & & & 432 & & 433 \\
\hline Code (3) & $121 ; 123 ; 131$ & 133 & & $421 ; 431$ & & & 423 \\
\hline Code (4) & $122 ; 123$ & $132 ; 133$ & 422 & & 432 & 423 & 433 \\
\hline Code (5) & $211 ; 213 ; 231 ; 411$ & 413 & 233 & 431 & & & 433 \\
\hline Code (6) & $212 ; 213$ & $412 ; 413$ & $232 ; 233$ & & 432 & & 433 \\
\hline Code (7) & $221 ; 231$ & & $223 ; 233$ & $421 ; 431$ & & 423 & 433 \\
\hline Code (8) & & & $222 ; 223 ; 232 ; 233 ; 422$ & & 432 & 423 & 433 \\
\hline Code (9) & $311 ; 313 ; 411$ & 413 & & $331 ; 333 ; 431$ & & & 433 \\
\hline Code (10) & $312 ; 313 ; 332$ & $412 ; 413$ & & 333 & 432 & & 433 \\
\hline Code (11) & & & & $321 ; 323 ; 331 ; 333 ; 421 ; 431$ & & 423 & 433 \\
\hline Code (12) & $322 ; 332$ & & 422 & $323 ; 333$ & 432 & 423 & 433 \\
\hline
\end{tabular}

sources $S_{1}, S_{2}$ and $S_{3}$, where:

$$
\left\{\begin{array}{l}
\mathrm{P}_{1}=\{E, V, M, \Omega\}=\{1 ; 2 ; 3 ; 4\} \\
\mathrm{P}_{2}=\{E,\{M, V\}, \Omega\}=\{1 ; 2 ; 3\} \\
\mathrm{P}_{3}=\{M,\{E, V\}, \Omega\}=\{1 ; 2 ; 3\}
\end{array}\right.
$$

In the planes $\mathrm{P}_{1} \mathrm{P}_{2} \mathrm{P}_{3}$, the first component of the intersection belongs to the plane $\mathrm{P}_{1}$ and is indicated by its position in the same plane. The second and third components obey the same principle respectively in the planes $\mathrm{P}_{2}$ and $\mathrm{P}_{3}$. Thus, for example:

$$
\begin{aligned}
& E \cap \Omega \cap M \rightarrow 131 \\
& \Omega \cap E \cap M \rightarrow 411
\end{aligned}
$$

The coding, which corresponds to the different intersections giving each element of $2^{\Omega}$ in the determination of the combined mass function, is given in Table 3.

Consequently, the combined mass function is the sum of the mass function products of $N D V I, M N D W I$ and $N D B a I$, for each element of $2^{\Omega}$, corresponding to the different codes inscribed in the box concerned.

For example, for the Code (1) and the element $\phi$ of $2^{\Omega}$, we have:

$$
\begin{gathered}
m(\phi)=N D V I_{x} \otimes M N D W I_{x} \otimes N D B a I_{x}(111)+N D V I_{x} \otimes M N D W I_{x} \\
\otimes N D B a I_{x}(131)+N D V I_{x} \otimes M N D W I_{x} \otimes N D B a I_{x}(411) \\
m(\phi)=\operatorname{NDVI}_{x}(E) * M N D W I_{x}(E) * N D B a I_{x}(M)+N D V I_{x}(E)_{x} * M N D W I_{x}(W) \\
* N D B a I_{x}(M)+N D V I_{x}(W)_{x} * M N D W I_{x}(E) * N D B a I_{x}(M)
\end{gathered}
$$

NB: The element of $2^{\Omega}$ which have a blank space according to the codes, are not written as triplet intersections of focal elements of the sources $S_{1}, S_{2}$ and $S_{3}$.

4) Measuring evidence and evaluation

\section{- Measuring evidence}

Once all the combined mass functions of the simple and multiples hypotheses 
Table 4. Elements of the combined mass function for the determination of credibility (Bel) et de plausibility $(P I s)$ functions.

\begin{tabular}{|c|c|c|c|c|c|c|c|c|c|}
\hline & & $\phi$ & $E$ & $V$ & $M$ & $\{E, V\}$ & $\{E, M\}$ & $\{M, V\}$ & $\Omega$ \\
\hline \multirow{5}{*}{$P 1 s$} & $\phi$ & $\begin{array}{l}\mathrm{m}(\phi) \\
\mathrm{m}(\phi)\end{array}$ & & & & & & & \\
\hline & $E$ & & $\begin{array}{l}m(E) \\
m(E)\end{array}$ & & & $m(\{E, V\})$ & $m(\{E, M\})$ & & $m(\Omega)$ \\
\hline & $V$ & & & $\begin{array}{l}m(V) \\
m(V)\end{array}$ & & $m(\{E, V\})$ & & $m(\{M, V\})$ & $m(\Omega)$ \\
\hline & $M$ & & & & $\begin{array}{l}m(M) \\
m(M)\end{array}$ & & $m(\{E, M\})$ & $m(\{M, V\})$ & $m(\Omega)$ \\
\hline & $\{E, V\}$ & & $\begin{array}{l}m(E) \\
m(E)\end{array}$ & $\begin{array}{l}m(V) \\
m(V)\end{array}$ & & $\begin{array}{l}m(\{E, V\}) \\
m(\{E, V\})\end{array}$ & & & $m(\Omega)$ \\
\hline \multirow{3}{*}{ Bel } & $\{E, M\}$ & & $\begin{array}{l}m(E) \\
m(E)\end{array}$ & & $\begin{array}{l}m(M) \\
m(M)\end{array}$ & & $\begin{array}{l}m(\{E, M\}) \\
m(\{E, M\})\end{array}$ & & $\mathrm{m}(\Omega)$ \\
\hline & $\{M, V\}$ & & & $\begin{array}{l}m(V) \\
m(V)\end{array}$ & $\begin{array}{l}m(M) \\
m(M)\end{array}$ & & & $\begin{array}{l}m(\{M, V\}) \\
m(\{M, V\})\end{array}$ & $m(\Omega)$ \\
\hline & $\Omega$ & & $\begin{array}{l}m(E) \\
m(E)\end{array}$ & $\begin{array}{l}m(V) \\
m(V)\end{array}$ & $\begin{array}{l}m(M) \\
m(M)\end{array}$ & $\begin{array}{l}m(\{E, V\}) \\
m(\{E, V\})\end{array}$ & $\begin{array}{l}m(\{E, M\}) \\
m(\{E, M\})\end{array}$ & $\begin{array}{l}m(\{M, V\}) \\
m(\{M, V\})\end{array}$ & $\begin{array}{l}m(\Omega) \\
m(\Omega)\end{array}$ \\
\hline
\end{tabular}

The determination of the values of the credibility function (resp function of plausibility) is made for each element, by color of cell, considering the sum of the expressions in black (resp in red).

of a pixel $x$ are determined, several approaches can be chosen to measure the evidence, in particular the credibility (Bel) and Plausibility (PIs) functions represented in Table 4.

For example, for an element $E$, we have:

$$
\begin{gathered}
\operatorname{Bel}(E)=m(E) \\
P l s(E)=m(E)+m(\{E, V\})+m(\{E, M\})+m(\Omega)
\end{gathered}
$$

The criterion of decision-making retained in this study is the maximum of plausibility.

\section{- Evaluation}

The evaluation consists in deciding on the quality of the classification carried out. Several methods exist. In this study, methods based on visual compliance analysis were used. This involves verifying in the field the correlations of the different entities provided by a classification. A synthesis of the methodology is shown in Figure 1.

The different results obtained during this process are presented in the following section.

\section{Results}

\subsection{NDVI, MNDWI and NDBaI Images}

The raw images produced by the NDVI, MNDWI and NDBaI sources are represented respectively by Figures $2-4$. 


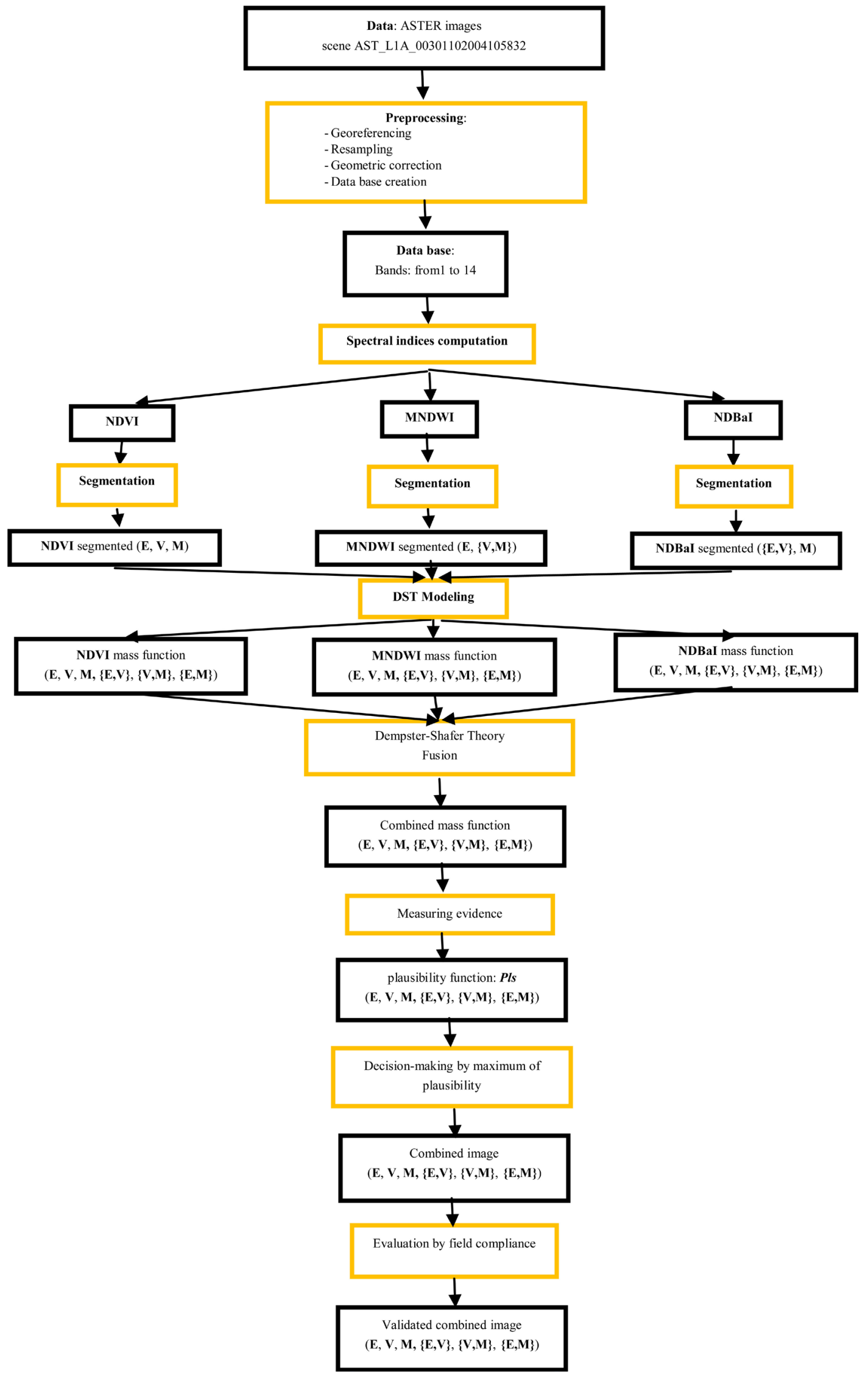

Figure 1. The flow chart of the methodology used. 


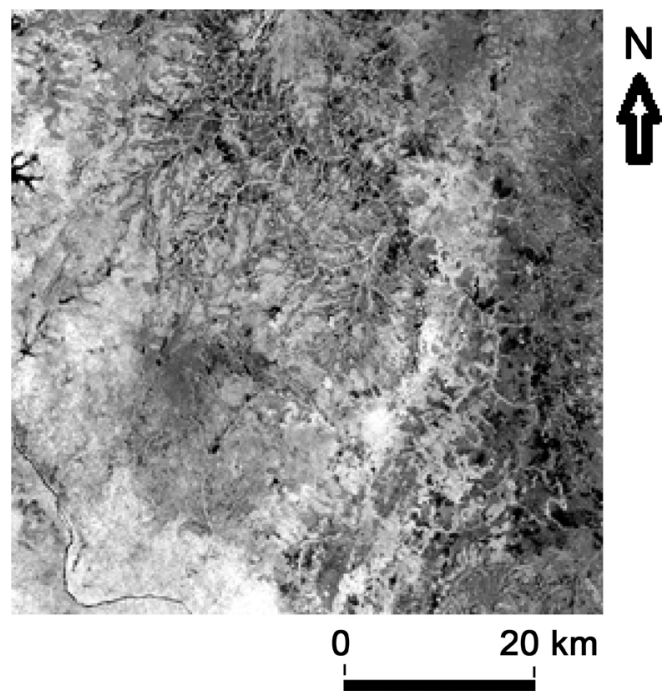

Figure 2. Raw $N D V I$ image.

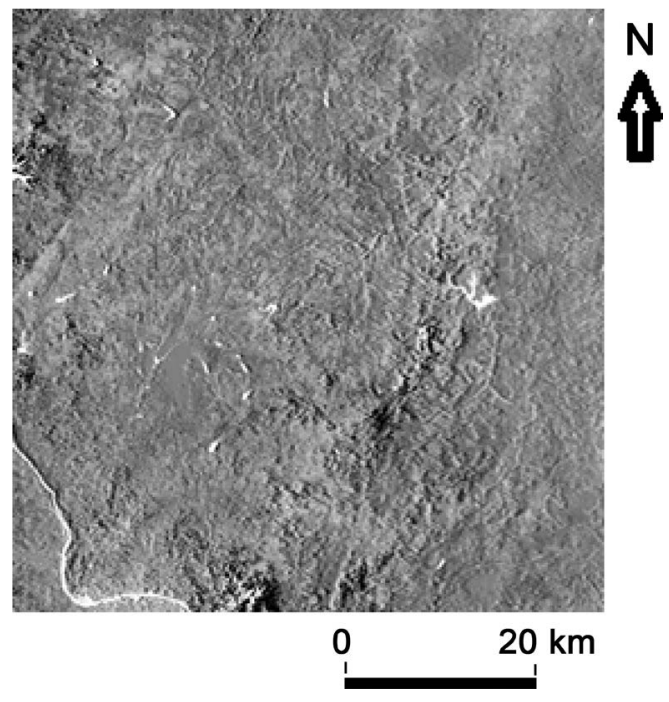

Figure 3. Raw $M N D W I$ image.

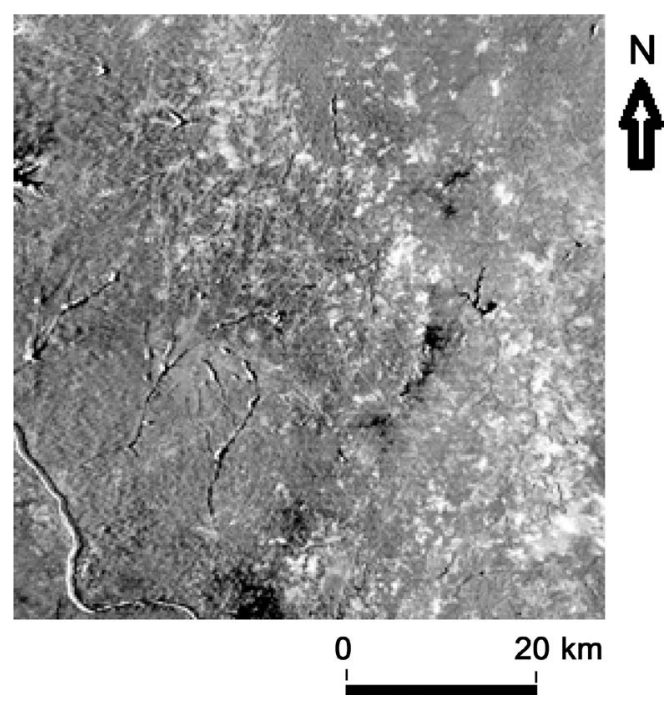

Figure 4. Raw NDBaI image. 
It was obtained from the interpretation of the $N D V I$ three entities:

- Areas with a very light gray to gray color indicate a very high chlorophyll activity. They correspond to the wooded savanna and the gallery forests;

- Gray to dark gray areas are indicative of very low chlorophyll activity. They characterize the degraded savanna;

- The zones of black to dark gray reveal an absence or very little vegetation cover. Therefore, they could represent water and mineral surfaces.

For the interpretation of the $M N D W I$, areas of whitish color would be areas with water presence, while other shades are attributed to vegetation and mineral surfaces.

On the NDBaI, the areas of blackish color would indicate the zones of absorption of heat, in this case the water; the areas of greyish to whitish color would represent the zones of varied reflection of heat whose strong reflections are whitish in color.

\subsection{Segmented Images NDVI, MNDWI and NDBaI}

The segmented images produced by the NDVI, MNDWI and NDBaI, sources, as a function of the thresholds in Table 1, are represented respectively in Figures 5-7.

The distribution of the pixels in the different classes of the segmented images is given in Table 5 .

\subsection{Combined and Segmented Image}

The proposed approach produces, from the characteristic segmented images derived from the NDVI, MNDWI and NDBaI, a combined image and classified in Figure 8 into six classes whose number of pixels per class is given in Table 6.

The analysis of Figure 8 shows an image classified into three absolute classes $(E, V, M)$ and three classes of confusion $(\{E, V\},\{M, V\},\{E, M\})$.

$\{E, V\}$ is the area of whitish color that characterizes the confusion between water and vegetation. It is observed in the vicinity of watercourses and water bo-

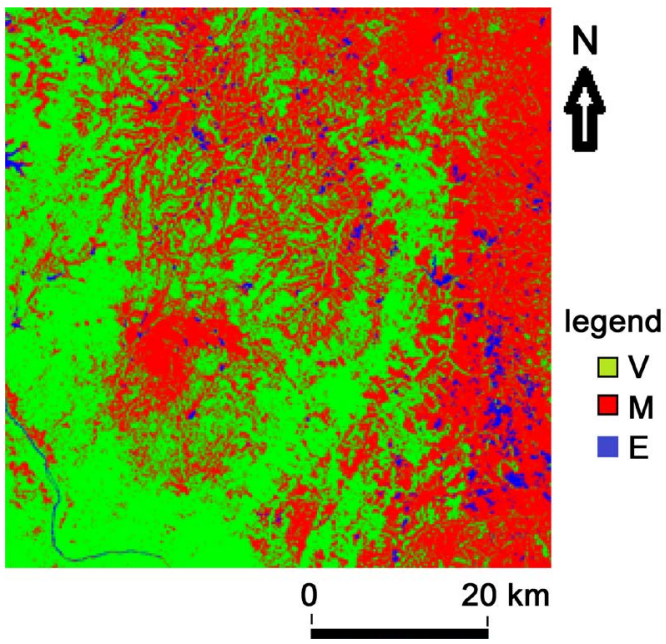

Figure 5. Segmented NDVI image. 


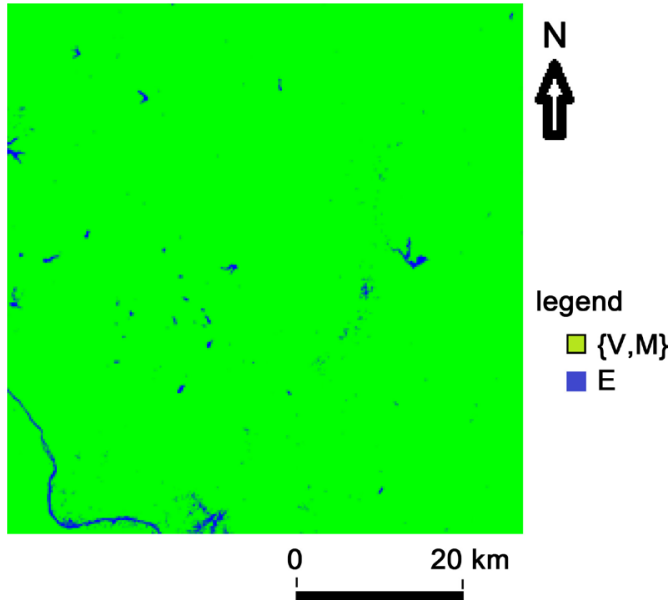

Figure 6. Segmented $M N D W I$ image.

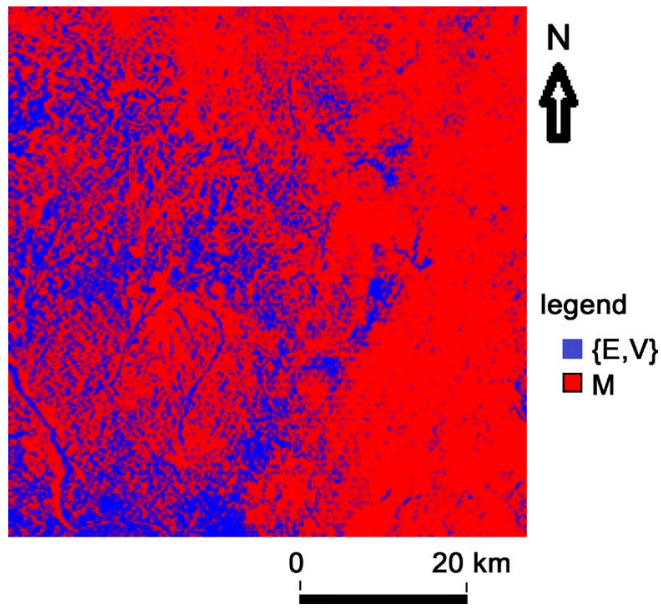

Figure 7. Segmented NDBaI image.

Table 5. Number (or percent) of pixels obtained per class for each segmented image.

\begin{tabular}{cccc}
\hline & $N D V I$ segmented & $M N D W I$ segmented & NDBaI segmented \\
\hline$E$ & $405,373(2.35 \%)$ & $133,641(0.78 \%)$ & 0 \\
$V$ & $8,525,447(49.51 \%)$ & 0 & 0 \\
$M$ & $8,289,180(48.14 \%)$ & 0 & $12,951,925(75.21 \%)$ \\
$\{E, V\}$ & 0 & 0 & $4,268,075(24.79 \%)$ \\
$\{M, V\}$ & 0 & $17,086,359(99.22 \%)$ & 0 \\
$\{E, V\}$ & 0 & 0 & $17,220,000(100 \%)$ \\
$\Omega$ & $17,220,000(100 \%)$ & $17,220,000(100 \%)$ &
\end{tabular}

dies. This is characteristic of gallery forests that are observed along or around the watercourses and bodies of water. It represents $0.354 \%$ of the area observed $\left(1371.573 \mathrm{~km}^{2}\right)$.

$\{M, V\}$ is the area of blackish color indicating confusion between vegetation and mineral surfaces. It occupies $38.220 \%$ of the observed surface area $\left(148,083.39 \mathrm{~km}^{2}\right)$ and corresponds to the areas covered by scattered grassy vegetation. 


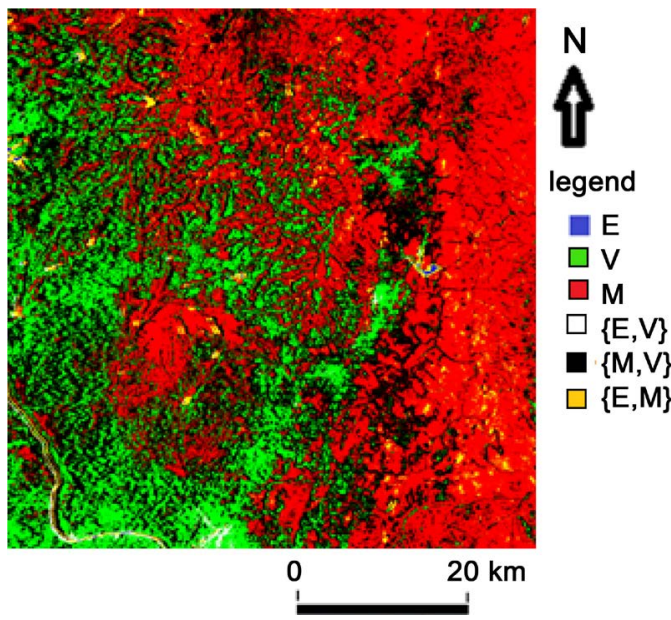

Figure 8. Combined and segmented image.

Table 6. Number (or percent) of pixels obtained per class for the combined and classified image.

\begin{tabular}{cc}
\hline Classes of image & Number of pixels obtained per class \\
\hline$E$ & $11,343(0.066 \%)$ \\
$V$ & $3,170,776(18.413 \%)$ \\
$M$ & $7,130,048(41.406 \%)$ \\
$\{E, V\}$ & $60,904(0.354 \%)$ \\
$\{M, V\}$ & $6,581,532(38.220 \%)$ \\
$\{E, M\}$ & $265,397(1.541 \%)$ \\
$\Omega$ & $17,220,000(100 \%)$ \\
\hline
\end{tabular}

$\{\mathrm{E}, \mathrm{M}\}$ is the area of yellowish color marking the confusion between water and mineral surfaces. It covers $1.541 \%$ of the area observed $\left(5970.604 \mathrm{~km}^{2}\right)$ and marks the places (where the vegetation is almost non-existent) with presence of water. This corresponds to places with abundant water and minerals (flats of water courses and bodies, water-saturated soils, very humid soils, etc.).

\section{Conclusions}

In this paper, an application of the Dempster-Shafer Theory has been proposed for the classification of pixels from Aster satellite images and the NDVI, $M N D W I$ and $N D B a I$, spectral indices in order to manage the potential inaccuracy and uncertainty related to images. The presented approach consists of merging the information of the segmented images coming from the indices NDVI, MNDWI and NDBaI.

This information was modeled by mass functions based on a model of normal law and simple support (two focal elements: the discernment framework and the potential grouping of the pixel to be classified). This produces a segmented image in six classes, including three absolute classes $(E, V, M)$ and three classes of confusion $(\{E, V\},\{M, V\},\{E, M\})$. The field verification, based on geographical coordinates of pixels of the said classes, made it possible to make a concordant 
interpretation thereof.

However, the interpretation of the results could be improved by a statistical study, in particular by the use of conformity matrix or confusion matrix. This model could be used, with appropriate adjustments, for other mapping purposes.

\section{References}

[1] Chen, X.L., Zhao, H.M., Li, P.X. and Yin, Z.Y. (2006) Remote Sensing Image Based on Analysis of the Relationship between Urban Heat Island and Land Use/Cover Changes. Remote Sensing of Environment, 104, 133-146.

https://doi.org/10.1016/j.rse.2005.11.016

[2] Lei, J., Li, Z. and Bruce, W. (2009) Analysis of Dynamic Thresholds for the Normalized Difference Water Index. Photogrammetric Engineering \& Remote Sensing, 75, 1307-1317. https://doi.org/10.14358/PERS.75.11.1307

[3] Srinivasan, A. and Richards, J.A. (1990) Knowledge-Based Techniques for Multisource Classification. International Journal of Remote Sensing, 11, 505-525. https://doi.org/10.1080/01431169008955036

[4] Bracker, H. (1996) Utilisation de la théorie de dempster/Shafer pour la classification d'images satellitaires à l'aide de données multi sources et multi temporelles. Thèse de l'Université de Rennes I, Rennes, 178 p.

[5] Bouakache, A., Khedam, R., Abbas, N., Ait Abdesselam, Y. and Belhadj-Aissa, A. (2008) Multi-Scale Satellite Images Fusion Using Dempster Shafer Theory. The IEEE International Conference on Information and Communication Technologies: from theory to applications-ICTTA 08, Damascus, Syria, 05-10 April 2008. https://doi.org/10.1109/ictta.2008.4530037

[6] Corgne, S. (2004) Modélisation prédictive de l'occupation des sols en contexte agricole intensif: Application à la couverture hivernale des sols en Bretagne. Thèse de l'université de Rennes II haute-Brétagne, Rennes, 226 p.

[7] Okaingni, J.-C., Kouamé, K.F. and Martin, A. (2010) Mapping Breastplates in Volcano-Sedimentary Area of Anikro-Kadiokro (Ivory Coast) Using the Dempster-Shafer Theory of Evidence. Revue Télédétection, 9, 19-32.

[8] Yager, R. (1986) A General Approach to Decision Making with Evidential Knowledge. In: Uncertainty in Artificial Intelligence, Kanal, L.N. and Lemmer, J., Eds, Elsevier Science Publishers, Amsterdam, 317-327.

https://doi.org/10.1016/B978-0-444-70058-2.50027-9

[9] Smets, P. (1990) Constructing the Pignistic Probability Function in a Context of Uncertainty. In: Uncertainty in Artificial Intelligence, Kanal, L.N. and Lemmer, J., Eds, Elsevier Science Publishers, Amsterdam, Vol. 5, 29-39. https://doi.org/10.1016/B978-0-444-88738-2.50010-5

[10] Abbas, N. (2009) Développement de modèles de fusion et de classification contex tuelle d'images satellitaires par la théorie de l'évidence et la théorie du raisonnement plausible et paradoxal. Thèse de Magister en traitement du signal et des images, USTHB, Alger, Algérie, 76 p.

[11] Rousse, J.W., Haas R.H., Schell J.A. and Deering, D.W. (1973) Monitoring vegetation systems in the great plains with ERTS. Third 80 ERTS Symposium, NASA SP-351, Washington DC, 10-14 December 1973, 309-317.

[12] Xu, H.Q. (2006) Modification of Normalized Difference Water Index (MNDWI) to Enhance Open Water Features in Remotely Sensed Imagery. International Journal 
of Remote Sensing, 27, 3025-3033. https://doi.org/10.1080/01431160600589179

[13] Zhao, H.M. and Chen, X.L. (2005) Use of Normalized Difference Bareness Index in Quickly Mapping Bare Areas from TM/ETM+. International Geoscience and Remote Sensing Symposium, Seoul, 25-29 July 1973, Vol. 3, 1666-1668.

Submit or recommend next manuscript to SCIRP and we will provide best service for you:

Accepting pre-submission inquiries through Email, Facebook, LinkedIn, Twitter, etc. A wide selection of journals (inclusive of 9 subjects, more than 200 journals)

Providing 24-hour high-quality service

User-friendly online submission system

Fair and swift peer-review system

Efficient typesetting and proofreading procedure

Display of the result of downloads and visits, as well as the number of cited articles Maximum dissemination of your research work

Submit your manuscript at: http://papersubmission.scirp.org/

Or contact jamp@scirp.org 